\title{
Descending Viewer Method for Fault Tolerant Control
}

\author{
K. Lenin \\ Prasad V. Potluri Siddhartha Institute of Technology, India
}

\begin{tabular}{l}
\hline Article Info \\
\hline Article history: \\
Received Jun 25, 2018 \\
Revised Aug 8, 2018 \\
Accepted Aug 25, 2018 \\
\hline Keywords: \\
Descending Method Viewer \\
Doubly Fed Induction \\
Generator \\
Fault tolerant control \\
Inter-turn short-circuit \\
Vector control \\
Wind turbine
\end{tabular}

\begin{abstract}
In this paper, descending viewer method (DVM) projected for finding and fault tolerant control of stator inter-turn short circuit faults in doubly-fed induction generators based in wind turbine. A process has been developed that allows the way from ostensible controllers designed for strong condition, to vigorous controllers designed for defective condition. Finally value of the rotor resistance estimated $\&$ is based on the use of the error between real and probable value of doubly fed induction generator (DFIG) in faulty condition, this will perk up the performance of this viewer. Simulation results show the reliability of the proposed DVM approach.
\end{abstract}

Copyright () 2018 Institute of Advanced Engineering and Science. All rights reserved.

\section{Corresponding Author:}

K. Lenin,

Prasad V. Potluri Siddhartha Institute of Technology,

Kanuru, Vijayawada, Andhra Pradesh -520007, India.

Email: gklenin@gmail.com

\section{INTRODUCTION}

Now a day's Wind energy generation is an economic \& one of the alternative source energy sources [1-7]. Systems such as DFIG-wind turbine, which have non-linear dynamics, have the regulator demean during wide variations of wind speed. Many techniques do not make use of the precise nonlinear DFIG-wind turbine model in the control design. Accordingly, the acquired controllers are usually not supported by recognized stability analysis and their performance cannot be particularly enumerated. Fault exposure and localization unit notice the incidence of fault and verify its temperament [8-19]. It can be recognized by examine the transform of the rotor resistance and suitable assessment has to be proceeded i.e. admitting the evasion or else cease the machine to perform a remedial protection. In this paper, DVM projected for finding and fault tolerant control of stator inter-turn short circuit faults in doubly-fed induction generators based in wind turbine. A process has been developed that allows the way from ostensible controllers designed for strong condition, to vigorous controllers designed for defective condition. Finally value of the rotor resistance estimated \& is based on the use of the error between real and probable value of DFIG in faulty condition, this will perk up the performance of this viewer. Simulation results show the reliability of the proposed DVM approach. Figure 1 shows block diagram of speed and reactive power controls of DFIG.

\section{MODELLING OF DOUBLY FED INDUCTION GENERATOR}

In the stator [7], [18-24] orientation frame $(\alpha s-\beta s)$, the mechanical/electrical energy alteration process is described by the equations [10], [16-28] of DFIG are given by: 


$$
\left\{\begin{array}{c}
V_{\alpha s}=R_{s} \cdot i_{\alpha s}+\frac{d \psi_{\alpha s}}{d t} \\
V_{\beta s}=R_{s} \cdot i_{\beta s}+\frac{d \psi_{\alpha s}}{d t} \\
V_{\alpha r}=R_{r} \cdot i_{\alpha r}+\frac{d \psi_{\alpha r}}{d t}+\omega_{r} \psi_{\beta r} \\
V_{\beta r}=R_{r} . i_{\beta r}+\frac{d \psi_{\alpha r}}{d t}-\omega_{r} \psi_{\alpha r}
\end{array}\right.
$$

Stator and rotor flux equations of are defined as below:

$$
\left\{\begin{array}{l}
\psi_{\alpha s}=L_{s} \cdot i_{\alpha s}+M_{s r} \cdot i_{\alpha r} \\
\psi_{\beta s}=L_{s} \cdot i_{\beta s}+M_{s r} \cdot i_{\beta r} \\
\psi_{\alpha r}=L_{r} \cdot i_{\alpha r}+M_{r s} \cdot i_{\alpha s} \\
\psi_{\beta r}=L_{r} \cdot i_{\beta r}+M_{r s} \cdot i_{\beta s}
\end{array}\right.
$$

Electromagnetic torque articulated by:

$$
C_{e m}=p \frac{M_{s r}}{L_{r}}\left(\psi_{d s} I_{q r}-\psi_{q s} I_{d r}\right)
$$

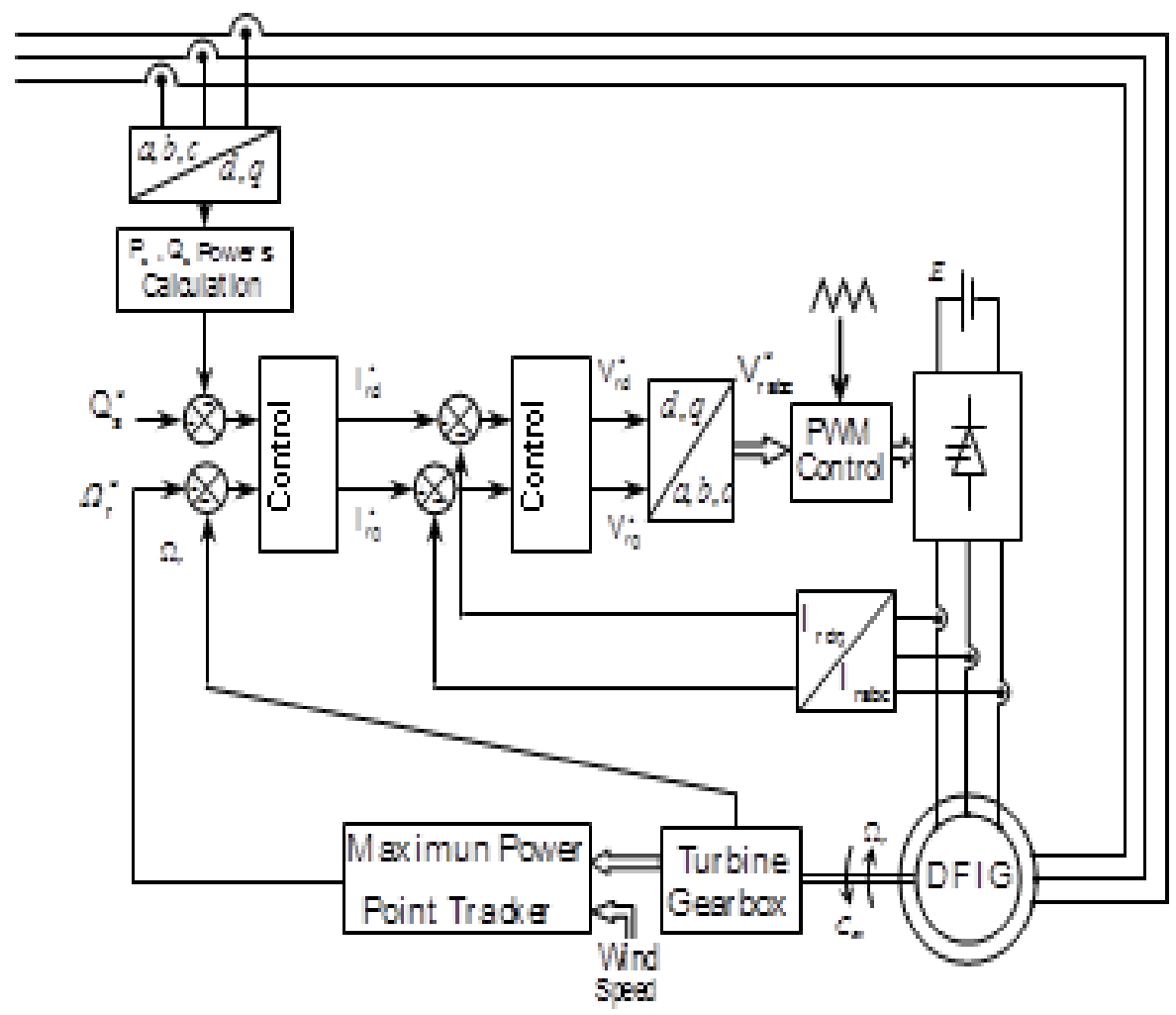

Figure 1. Block diagram of speed and reactive power controls of DFIG 
Standard vector control with stator flux [18], [28-29] of the DFIG is shown in Figure 2. The stator flux vector will be associated on the ' $\mathrm{d}$ ' axis \& the stator voltage vector on the ' $\mathrm{q}$ ' axis, this final restriction is complimentary to acquire a easy control model.

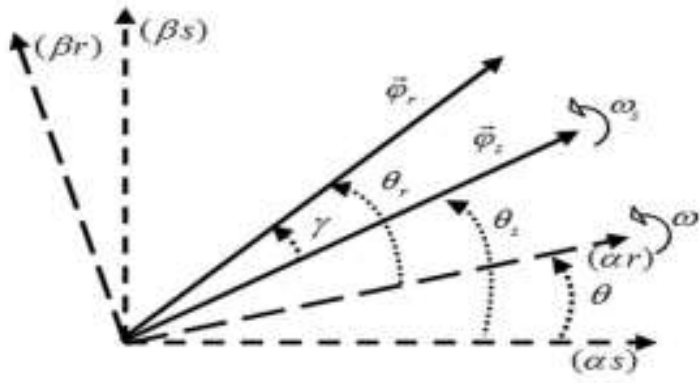

Figure 2. Respective position of the references $(\alpha \mathrm{s}, \beta \mathrm{s})$ and $(\alpha \mathrm{r}, \beta \mathrm{r})$

In a fixed reference frame $(\alpha s-\beta s)$ [12], [14-17] DFIG electrical equations in the state-space can be articulated as below:

$$
\left\{\begin{array}{l}
\frac{d X}{d t}=A X+B U \\
Y=C X
\end{array}\right.
$$

with

$$
\begin{aligned}
& X=\left[\begin{array}{llll}
i_{\alpha s} & i_{\beta s} & \Phi_{\alpha r} & \Phi_{\beta r}
\end{array}\right]^{t}, Y=\left(\begin{array}{c}
i_{\alpha s} \\
i_{\beta s}
\end{array}\right) \text { and } u=\left[\begin{array}{llll}
u_{\alpha s} & u_{\beta s} & u_{\alpha r} & u_{\beta r}
\end{array}\right]^{t} \\
& A=\left[\begin{array}{ll}
A_{11} & A_{12} \\
A_{21} & A_{22}
\end{array}\right], B=\left[\begin{array}{ll}
B_{11} & B_{12} \\
B_{21} & B_{22}
\end{array}\right], \quad I=\left[\begin{array}{ll}
1 & 0 \\
0 & 1
\end{array}\right] \text { and } J=\left[\begin{array}{cc}
0 & -1 \\
1 & 0
\end{array}\right]
\end{aligned}
$$

with

$$
\begin{aligned}
& A_{11}=\left[\begin{array}{cc}
\left(\frac{-1}{\sigma \tau_{s}}-\frac{L_{m}^{2}}{\tau_{s} \sigma L_{s} L_{r}}\right) \\
0 & \left(\frac{-1}{\sigma \tau_{s}}-\frac{L_{m}^{2}}{\tau_{s} \sigma L_{s} L_{r}}\right)
\end{array}\right], A_{12}=\left[\begin{array}{cc}
\frac{L_{m}}{\tau_{r} \sigma L_{s} L_{r}} & \frac{w L_{m}}{\sigma L_{s} L_{r}} \\
\frac{w L_{m}}{\sigma L_{s} L_{r}} & \frac{L_{m}}{\tau_{r} \sigma L_{s} L_{r}}
\end{array}\right] \\
& A_{21}=\left[\begin{array}{cc}
\frac{L_{m}}{\tau_{r}} & 0 \\
0 & \frac{L_{m}}{\tau_{r}}
\end{array}\right], A_{22}=\left[\begin{array}{cc}
\frac{-1}{\tau_{r}} & -w \\
w & \frac{-1}{\tau_{r}}
\end{array}\right] \\
& B_{11}=\left[\begin{array}{cc}
\frac{1}{\sigma L_{s}} & 0 \\
0 & \frac{1}{\sigma L_{s}}
\end{array}\right], B_{12}=\left[\begin{array}{cc}
\frac{-L_{m}}{\sigma L_{s}} & 0 \\
0 & \frac{-L_{m}}{\sigma L_{s} L_{r}}
\end{array}\right], B_{21}=\left[\begin{array}{ll}
0 & 0 \\
0 & 0
\end{array}\right] \text { and } B_{22}=\left[\begin{array}{ll}
1 & 1 \\
1 & 1
\end{array}\right]
\end{aligned}
$$

And $\sigma=1-L_{m}^{2} /\left(L_{s} L_{r}\right), w=p \Omega_{m e c}$ 
where $R_{s}$ and $R_{r}$ are the stator and rotor resistance, respectively. $L_{s}, L_{r}$ and $L_{m}$ are the stator and rotor full inductance, the magnetization inductance, respectively. The electromagnetic torque [15], [26-28] equation can be written as,

$$
C_{e}=\frac{3}{2} p \frac{L_{m}}{L_{r}}\left(\Phi_{\alpha r} i_{\beta s}-\Phi_{\beta r} i_{\alpha s}\right)
$$

An inter-turn fault for a stator phase winding is a consequence of the worsening of insulation between the individual coils. A Short circuit in stator phase winding alters the symmetrical stator current. To forecast the electrical performance from the stator supply due to an inter-turn fault, it would emerge that the impedance of the short-circuited stator winding has been diminished [5-33]. The degree to which its impedance will be diminished is depend on the rigorousness of the fault. To simulate the failure, the impedance of the stator phase winding is diminished by placing a resistor in parallel with the winding, as shown in Figure 3 [22-23]. Stator resistance matrix redrafted as follows, yet, the matrix of stator voltages unaffected.

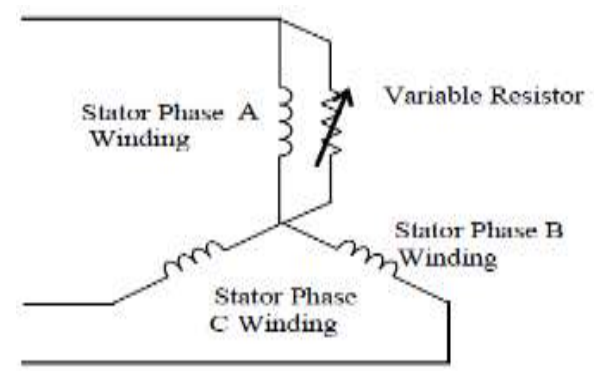

Figure 3. Stator winding configuration with the inter-turn short circuit fault in phase 'A'

$$
\left[R_{s}\right]=\left[\begin{array}{cccc}
(1-\mu) R_{s} & 0 & 0 & \gamma \cdot R_{s} \\
0 & R_{s} & 0 & 0 \\
0 & 0 & R_{s} & 0 \\
0 & 0 & 0 & \mu \cdot R_{s}
\end{array}\right]
$$

« $\mu$ fraction of the number of shorted turns of phase «a , then we have a strong portion of a fraction $1-\mu$ of turns and the phases "b" and "c" are also strong. New inductance stator matrix [20-25] is given as follows:

$$
\left[L_{s s}\right]=L_{f s} \operatorname{diag}[(1-\mu) 111 \mu]+M_{s}\left[\begin{array}{cccc}
(1-\mu)^{2} & -\frac{(1-\mu)}{2} & -\frac{(1-\mu)}{2} & \mu(1-\mu) \\
-\frac{(1-\mu)}{2} & 1 & -\frac{1}{2} & -\frac{\mu}{2} \\
-\frac{(1-\mu)}{2} & -\frac{1}{2} & 1 & -\frac{\mu}{2} \\
\mu(1-\mu) & -\frac{\mu}{2} & -\frac{\mu}{2} & \mu^{2}
\end{array}\right]
$$

Matrix of mutual inductances [2-30] is given as follows\& Rotor inductance matrix [21], [24-25] remains equal to that of the strong cases. 


$$
\left[M_{s r}\right]=M_{s}\left[\begin{array}{ccc}
(1-\mu) \cos \left(\theta_{r}\right) & (1-\mu) \cos \left(\theta_{r}+\frac{2 \pi}{3}\right) & (1-\mu) \cos \left(\theta_{r}-\frac{2 \pi}{3}\right) \\
\cos \left(\theta_{r}-\frac{2 \pi}{3}\right) & \cos \left(\theta_{r}\right) & \cos \left(\theta_{r}+\frac{2 \pi}{3}\right) \\
\cos \left(\theta_{r}+\frac{2 \pi}{3}\right) & \cos \left(\theta_{r}-\frac{2 \pi}{3}\right) & \cos \left(\theta_{r}\right) \\
\mu \cos \left(\theta_{r}\right) & \mu \cos \left(\theta_{r}+\frac{2 \pi}{3}\right) & \mu \cos \left(\theta_{r}-\frac{2 \pi}{3}\right)
\end{array}\right]
$$

\section{DESCENDING VIEWER METHOD}

If the system is noticeable, then the intention of the viewer is to provide the most excellent evaluation of the state variables from the measurements on the output " $y$ " and the input " $u$ ".

The viewer [32-33] defined as follows,

$$
\hat{x}=f(\hat{x}, y, u, t)+\Lambda u_{s}
$$

A nonlinear system is considered [6-19] by the following equation,

$$
\left\{\begin{array}{l}
\dot{\mathrm{x}}(\mathrm{t})=\mathrm{f}(x(\mathrm{t}), \mathrm{u}(\mathrm{t})) \\
\mathrm{y}(\mathrm{t})=\mathrm{C} \mathrm{x}(\mathrm{t})
\end{array}\right.
$$

Or. $x \in R^{n}, u \in R^{m}$ et $y \in R^{p}$ mode by:

The system is noticeable, \& the system (10), the viewer [3-8-11-13] is decided by descending

$$
\begin{aligned}
& \hat{\mathrm{x}}=\mathrm{f}(\hat{\mathrm{x}}(\mathrm{t}), \mathrm{u}(\mathrm{t}))+\Lambda \mathrm{I}_{\mathrm{s}} \\
& I_{s}=\operatorname{Sign}(S)=\left[\operatorname{sign}\left(s_{1}\right), \operatorname{sign}\left(s_{2}\right) \ldots \operatorname{sign}\left(s_{p}\right),\right]^{\mathrm{T}}
\end{aligned}
$$

where $\operatorname{sign}($.$) is sign function and is the then slide surface is given by,$

$$
\begin{aligned}
& S=N \bar{C} \bar{x}=\left[s_{1}, s_{2} \ldots \ldots s_{p}\right] \\
& \bar{x}=x-\hat{x}
\end{aligned}
$$

$N \in R^{P x P}$ is a matrix to be indicated.

Therefore, the dynamics of the observation error turn into as follows:

$$
\stackrel{\bullet}{x}=\mathrm{f}(x, \mathrm{u})-\hat{\mathrm{f}}(\hat{x}, \mathrm{u})+\Lambda \mathrm{I}_{\mathrm{s}}
$$

The descending surface $S=0$ is striking if: 
$S_{i} \dot{S}_{i}<0$ for $i=1,2, \ldots . p$.

This circumstance describes the area for which the slip mode is present. In the duration of slip, the dynamics of the estimation error are condensed from the order n (preliminary system) to the order of $n-p$ (condensed order equal system). Then the assets of this condensed dynamics are examined. The method of equivalent control has been utilized for the examination. The purpose of the expression of the condensed dynamic range is based on the computation of the equivalent $\tilde{\mathrm{I}}_{\mathrm{s}}$ switching vector on the switching surface.

As of the condition of invariance $S \equiv 0$ and $\dot{S} \equiv 0$.

$$
\dot{S}=N C \bar{x}=N C\left(\mathrm{f}(x, \mathrm{u})-\hat{\mathrm{f}}(\hat{x}, \mathrm{u})+\Lambda \tilde{\mathrm{I}}_{\mathrm{s}}\right)=0
$$

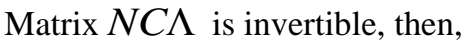

$$
\tilde{\mathrm{I}}_{\mathrm{s}}=(N C \Lambda)^{-1} N C(\mathrm{f}(x, \mathrm{u})-\hat{\mathrm{f}}(\hat{x}, \mathrm{u}))
$$

The replacement of $\tilde{\mathrm{I}}_{\mathrm{s}}$ in (15) has permitted us to acquire the condensed dynamics as,

$$
\dot{\bar{x}}_{e q}=\left[I-\Lambda(N C \Lambda)^{-1} N C\right][\mathrm{f}(x, \mathrm{u})-\hat{\mathrm{f}}(\hat{x}, \mathrm{u})]
$$

At last, the viewer amalgamation selects the matrices $N$ and $\Lambda$ so as to make sure that the same time the magnetism of the sliding surface and stability of the condensed dynamic range.

\section{DVM PROJECTED FOR FINDING AND FAULT TOLERANT CONTROL OF STATOR INTER-TURN SHORT CIRCUIT FAULTS IN DOUBLY-FED INDUCTION GENERATOR} as follows,

The descending method viewer for the evaluation of the doubly-fed induction generator flows

$$
\begin{aligned}
& \left\{\begin{array}{l}
\hat{x} 1=-a x 1+\frac{R_{r} L_{m}}{a L_{r}} \hat{x} 3+\frac{L_{m}}{b} \hat{x} 4 p \times 5+\frac{1}{\sigma L_{s}} v_{\alpha s}+\frac{L_{m}}{b} v_{\alpha r}+\Lambda_{1}^{T} I_{S} \\
\dot{\hat{x}} 2=-a x 2-\frac{L_{m}}{b} \hat{x} 3 p \times 5+\frac{R_{r} L_{m}}{a L_{r}} \hat{x} 4+\frac{1}{\sigma L_{s}} v_{\beta s}+\frac{L_{m}}{b} v_{\beta r}+\Lambda_{2}^{T} I_{S} \\
\dot{\hat{x}} 3=\frac{R_{r} L_{m}}{L_{r}} x 1-\frac{R_{r}}{L_{r}} \hat{x} 3-\hat{x} 4 p x 5+v_{\alpha r}+\Lambda_{3}^{T} I_{S} \\
\hat{\hat{x}} 4=\frac{R_{r} L_{m}}{L_{r}} \times 2-\frac{R_{r}}{L_{r}} \hat{x} 4+\hat{x} 3 p \times 5+v_{\beta r}+\Lambda_{4}^{T} I_{S} \\
\dot{\hat{x}} 5=d(\hat{x} 3 \times 2-\hat{x} 4 x 1)-\frac{T_{r}}{J}-\frac{f_{v}}{J} \times 5+q_{1}(x 5-\hat{x} 5)+\Lambda_{5}^{T} I_{S}
\end{array}\right. \\
& a=\frac{1}{\sigma L_{s}}\left(R_{s}+R_{r} \frac{L_{m}^{2}}{L_{r}^{2}}\right), b=\sigma L_{s} L_{r}, \sigma=1-\frac{L_{m}^{2}}{L_{s} L_{r}}
\end{aligned}
$$


With $\hat{x}=\left[\begin{array}{lllll}\hat{i}_{\alpha s} & \hat{i}_{\beta s} & \hat{\Phi}_{\alpha r} & \hat{\Phi}_{\beta r} & \hat{w}_{r}\end{array}\right]^{T}$ and $\hat{y}=\left[\begin{array}{lll}\hat{i}_{\alpha s} & \hat{i}_{\beta s} & \hat{w}_{r}\end{array}\right]^{T}$

$$
I_{S}=\left[\operatorname{sign}\left(\mathrm{S}_{1}\right) \operatorname{sign}\left(\mathrm{S}_{2}\right)\right]^{T} \text { and }\left\{\begin{array}{l}
S_{1}=x_{1}-\hat{x_{1}} \\
S_{2}=x_{2}-\hat{x_{2}}
\end{array}\right.
$$

$\mathrm{S}_{1}, \mathrm{~S}_{2}$ symbolize the descending surfaces.

The increase: $q_{1}, \Lambda_{1}^{T}, \Lambda_{2}^{T}, \Lambda_{3}^{T}, \Lambda_{4}^{T}, \Lambda_{5}^{T}$ are computed to guarantee the asymptotic convergence of the error estimation \& given by:

$$
\begin{aligned}
& {\left[\begin{array}{l}
\Lambda_{1}^{T} \\
\Lambda_{2}^{T}
\end{array}\right]=D^{-1}\left[\begin{array}{ll}
\delta_{1} & 0 \\
0 & \delta_{2}
\end{array}\right] \text { and } D=\frac{1}{\left(a^{2}+\left(k p x_{5}\right)^{2}\right)}\left[\begin{array}{cc}
a & -k p x_{5} \\
k p x_{5} & a
\end{array}\right]} \\
& {\left[\begin{array}{ll}
\Lambda_{31} & \Lambda_{32} \\
\Lambda_{41} & \Lambda_{42}
\end{array}\right]=\left[\left(\begin{array}{cc}
-c & -p x_{5} \\
p x_{5} & -c
\end{array}\right)\left(\begin{array}{cc}
q_{3} & 0 \\
0 & q_{4}
\end{array}\right)\right]\left(\begin{array}{cc}
\delta_{1} & 0 \\
0 & \delta_{2}
\end{array}\right)} \\
& {\left[\begin{array}{ll}
\frac{\Lambda_{51}}{\delta_{1}} & \frac{\Lambda_{52}}{\delta_{2}}
\end{array}\right]=d\left[x_{2}-x_{1}\right]}
\end{aligned}
$$

such as:

$$
\left\{\begin{array} { l } 
{ \delta _ { 1 } > | e _ { 3 } | _ { \text { max } } } \\
{ \delta _ { 2 } > | e _ { 4 } | _ { \text { max } } }
\end{array} \text { and } \left\{\begin{array}{l}
q_{1}>0 \\
q_{3}>0 \\
q_{4}>0
\end{array}\right.\right.
$$

The residual signal is computed as follows, $r=[y-\hat{y}] \& r_{0}$ as the detection threshold (lower limit), which is defined according to several pre-specified system performance. The object is to find out the mechanism of adjustment of the speed and the resistance of the rotor. The viewer structure is based on the DFIG model in the stator reference.

\section{SIMULATION STUDY}

\subsection{Phase 1 strong operation}

To illustrate the performance of the projected control, several modes of operation have been viewed Figure 4 and 5 . The primary mode match up to the over speed operation. Then it treated as the strong functioning. Finally, the study bang of the following disturbances: variation of the rotor resistance and stator inter-turn short circuit fault.
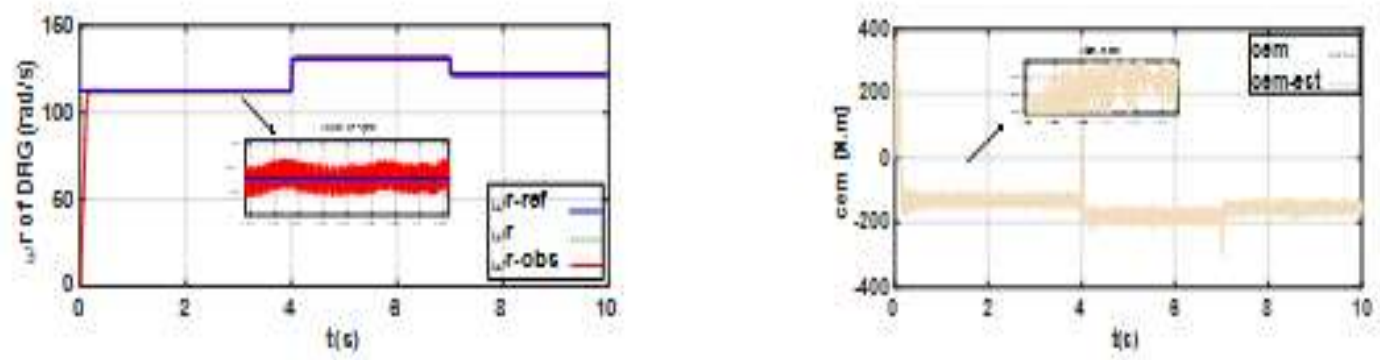

Figure 4. Rotation speed and electromagnetic torque of the DFI 

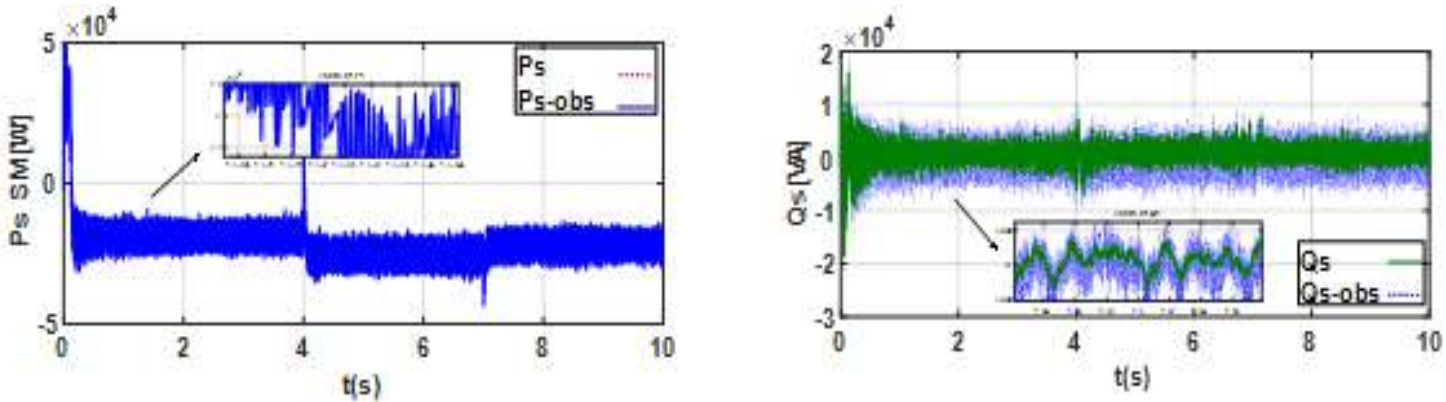

Figure 5. Active and reactive stator power with variation of wind speed
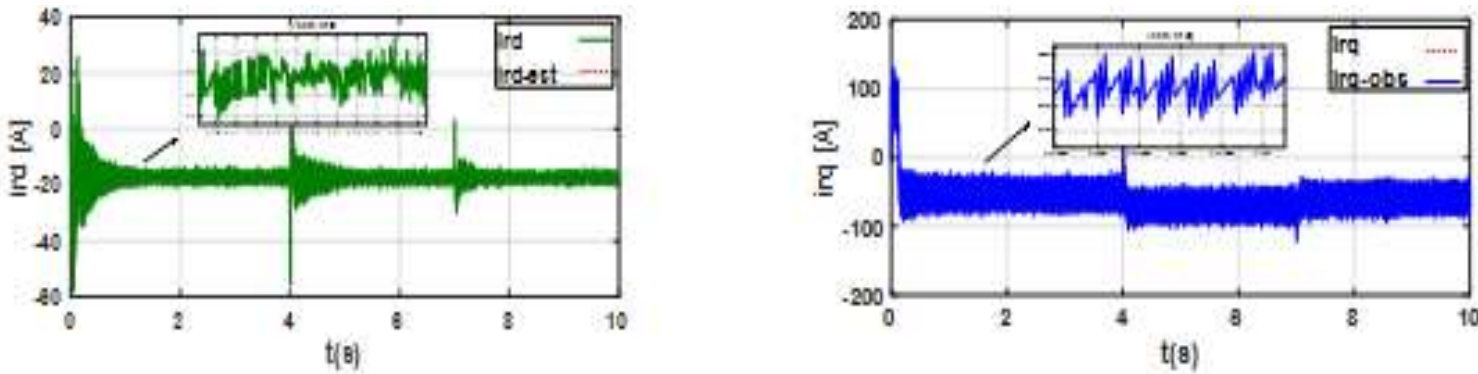

Figure 6. Rotor currents $\left(i_{r d}, i_{r q}\right)$ with variation of wind speed
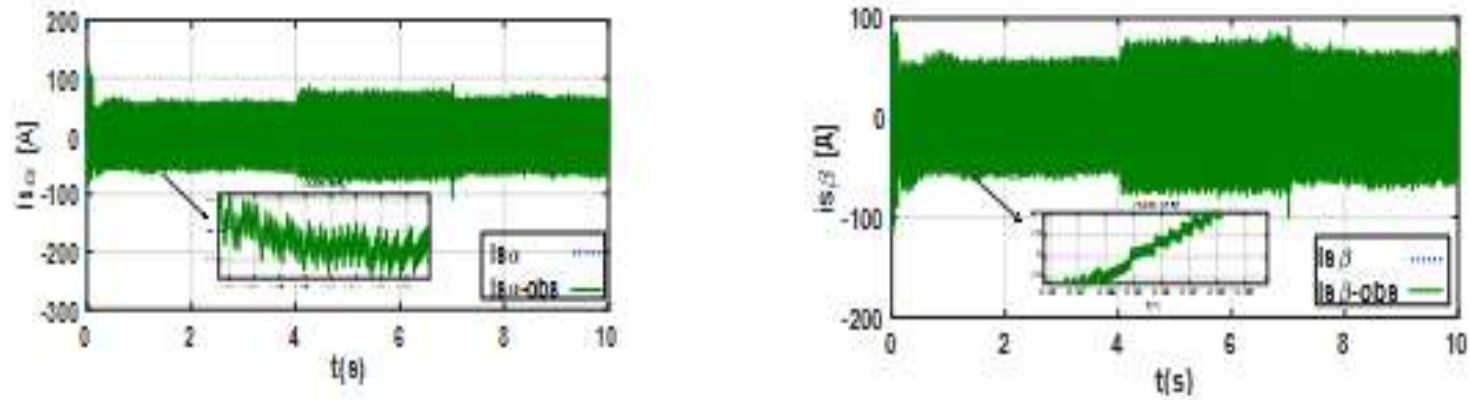

Figure 7. Stator currents $\left(I_{s \alpha}, I_{s \beta}\right)$ with variation of wind speed

\subsection{Process with stator inter-turn short circuit fault and for variation of the rotor resistance}

Figures 8, 9, 10, 11 indicates the stator inter-turn short circuit fault and rotor resistance variation. Figure 12 shows principle of an adaptive descending viewer method.
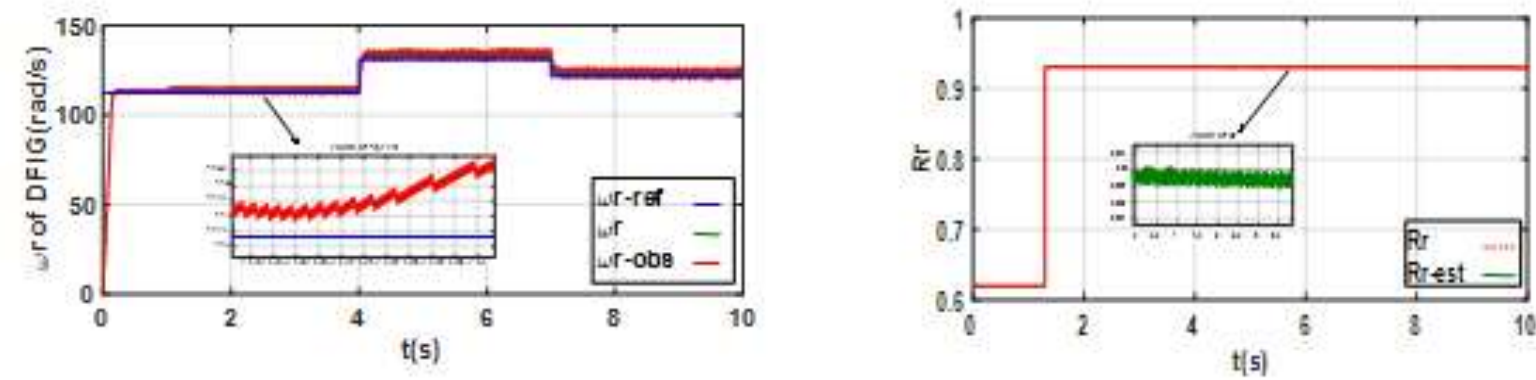

Figure 8. Rotation speed and observed rotor resistance of the DFIG 

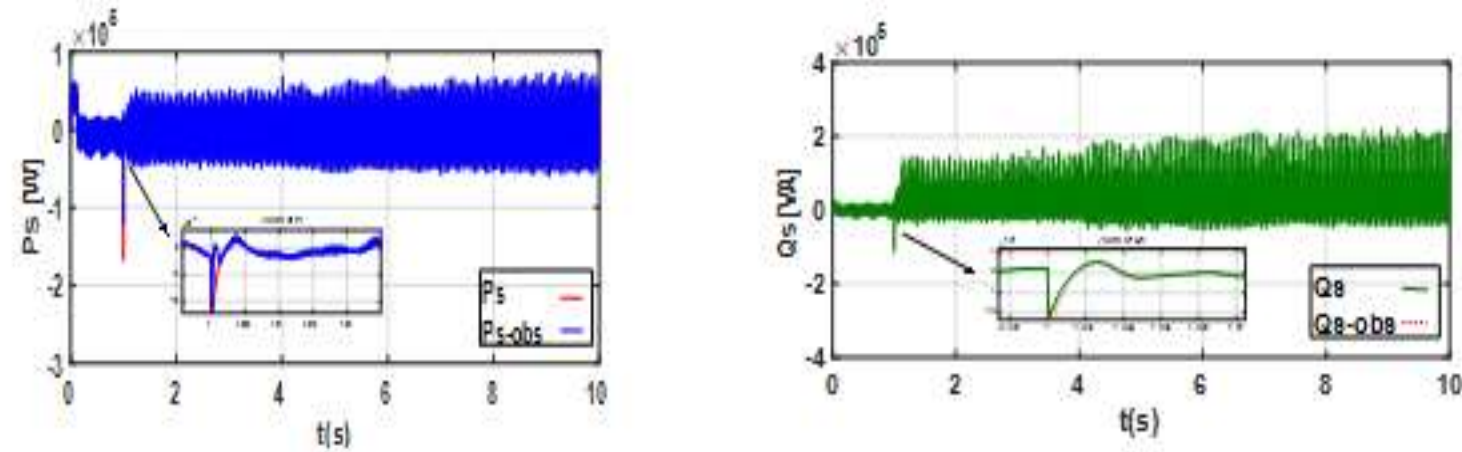

Figure 9. Active and reactive stator power
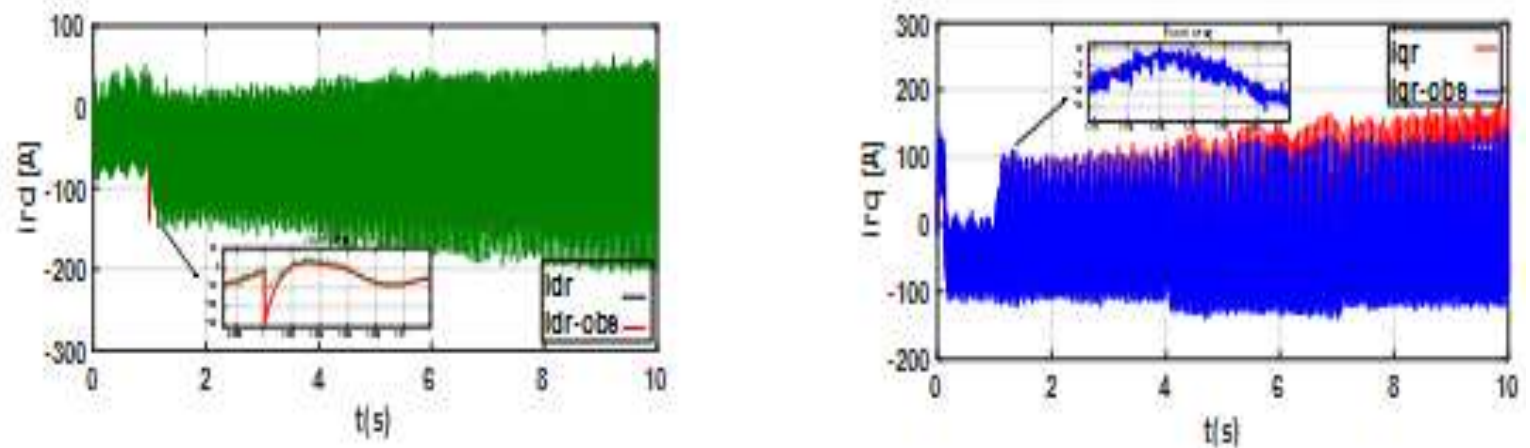

Figure 10. Park's rotor currents $\left(i_{r d}, i_{r q}\right)$
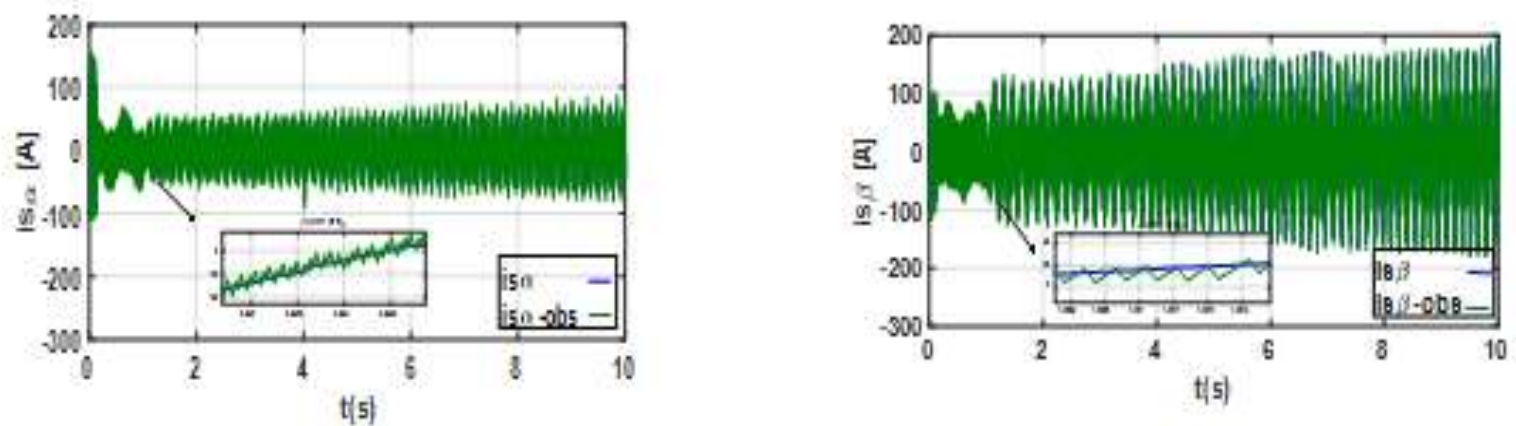

Figure 11. Stator Current $\left(I_{s \alpha}, I_{s \beta}\right)$

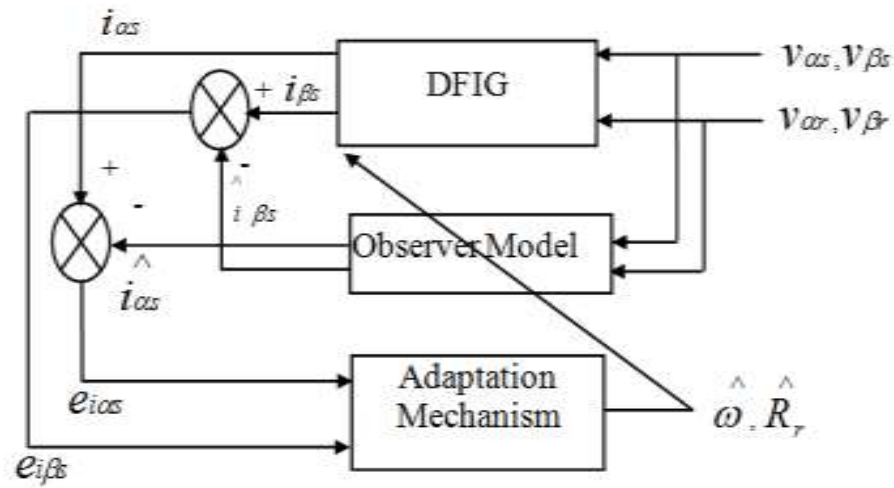

Figure 12. Principle of an adaptive descending viewer method 
The current rotational speed of the ripple relative to the strong operation is noted, and in accumulation it is not affected by the variation of the rotor resistance. The active and reactive stator power, direct, quadrature rotor currents and the stator phase current have oscillations of elevated amplitudes than those corresponding to the strong operation. This augment is due to the stator inter-turn short circuit fault. As following, the control with descending viewer method has high-quality performances of heftiness and accuracy of function in dilapidation against stator inter-turn short circuit fault and the rotor resistance variation.

\section{CONCLUSION}

In this research paper, descending method viewer method applied to DFIG, based on the assessment of the value of the rotor resistance. The assessment of the rotor resistance is based on the use of the error between real and estimated value of DFIG in flawed condition \& it need to perk up the performances of this viewer. In flawed conditions, the machine is unbalanced and noteworthy augment of stator and rotor currents is formed. In the proposed control system, the speed remains equal to its reference value and the overshoot currents cannot be evaded. When the current is not beyond the tolerable level, the DFIG prolong to activate with besmirched performance until its revamp. So, it's constantly obligatory to accomplish early on fault detection to control the damage. The universal control scheme introduces elevated performances of heftiness and steadiness with accuracy. The rotor resistance $R_{r}$ estimated with little error\& the estimation of rotor resistance can be helpful for improving the vibrant characters of controller by the adaptive descending viewer method.

\section{REFERENCES}

[1] Jingchuan Li, Longya Xu and Zheng Zhang, "An adaptive sliding-mode observer for induction motor sensorless speed control," in IEEE Transactions on Industry Applications, vol. 41, no. 4, pp. 1039-1046, July-Aug. 2005.

[2] A. Yazidi, H. Henao, G. -. Capolino, D. Casadei and F. Filippetti, "Double-fed three-phase induction machine abc model for simulation and control purposes," 31st Annual Conference of IEEE Industrial Electronics Society, 2005. IECON 2005., Raleigh, NC, 2005, pp. 6 pp.

[3] A Ferdjouni, Diagnostic des defauts à l'aide d'observateurs application a la machine asynchrone. Doctorat d'état : Blida : Universitée Saad Dahleb : 2007

[4] C. Wei, Z. Zhang, J. Zeng and W. Qiao, "Stator current-based sliding mode observer for sensorless vector contorl of doubly-fed induction geneartors," 2015 IEEE Energy Conversion Congress and Exposition (ECCE), Montreal, QC, 2015, pp. 4165-4171.

[5] C. Thybo, "Fault-tolerant Control of Inverter Fed Induction Motor Drives," PhD Thesis, University of Aalborg, 1999.

[6] D. Kouchih, M. Tadjine and M.S. Boucherit, "Improved direct torque control of induction motors using adaptive observer and sliding mode control," Archives of Control Sciences, vol. 23; pp. 361-376, 2013.

[7] F. Poitiers, T. Bouaouiche, M. Machmoum, "Advanced control of a doubly-fed induction generator for wind energy conversion", Electric Power Systems Research, vol. 79, no. 7, pp. 1085-1096, July 2009.

[8] H. Chekireb, M. Tadjine. "Lyapunov based on cascaded non-linear control of induction machine, nonlinear dynamics and Systems Theory, "Nonlinear Dynamics and Systems Theory, vol. 7, no. 3, pp. 253-266, 2007.

[9] F. Poitiers: Etude et Commande de Génératrices Asynchrones pour l'Utilisation de l'Energie Eolienne.Thèse de doctorat, Nantes, (2003). Eolienne.Thèse de doctorat, Nantes, (2003).

[10] F. Poitiers, T. Bouaouiche, "Advanced control of a doubly-fed induction generator for wind energy conversion," Electric Power Systems Research, vol. 79, no. 7, pp. 1085-1096, July 2009.

[11] M. Ghanes. Observation et commande de la machine asynchrone sans capteur mécanique. Thèse de doctorat. Université de Nantes. 2005

[12] A. Xu, Observateurs adaptatifs non linéaires et diagnostic de pannes. Thèse de Doctorat, Université de Rennes1, Septembre 2002

[13] R.A.Salas. Développement des lois de commandes avec observateurs pour machine asynchrone. Thèse de doctorat. Institut national polytechnique de Grenoble, 17 Dec 2007.

[14] K. Rothenhagen and F. W. Fuchs, "Current Sensor Fault Detection, Isolation, and Reconfiguration for Doubly Fed Induction Generators," in IEEE Transactions on Industrial Electronics, vol. 56, no. 10, pp. 4239-4245, Oct. 2009.

[15] K. Rothenhagen and F. W. Fuchs, "Advanced sensor fault detection and control reconfiguration of wind power plants using doubly fed induction generators," 2008 IEEE Power Electronics Specialists Conference, Rhodes, 2008, pp. 913-919.

IJAPE Vol. 7, No. 3, December 2018: 199 - 210 
[16] K. Rothenhagen and F. W. Fuchs, "Doubly Fed Induction Generator Model-Based Sensor Fault Detection and Control Loop Reconfiguration," in IEEE Transactions on Industrial Electronics, vol. 56, no. 10, pp. 4229-4238, Oct. 2009.

[17] K. Rothenhagen and F. W. Fuchs, "Model-based fault detection of gain and offset faults in Doubly Fed Induction Generators," 2009 IEEE International Symposium on Diagnostics for Electric Machines, Power Electronics and Drives, Cargese, 2009, pp. 1-6.

[18] L. Sun, Z. Mi, Y. Yu, T. Wu and H. Tian, "Active power and reactive power regulation capacity study of DFIG wind turbine," 2009 International Conference on Sustainable Power Generation and Supply, Nanjing, 2009, pp. 1-6.

[19] H. Jamouli, Génération de résidus directionnels pour le diagnostic des systèmes linéaires stochastiques et la commande tolérante aux défauts. Thèse de Doctorat, Université Henri Poincaré, Nancy-I, France, Décembre 2003.

[20] M. B. Abadi et al., "Detection of stator and rotor faults in a DFIG based on the stator reactive power analysis," IECON 2014 - 40th Annual Conference of the IEEE Industrial Electronics Society, Dallas, TX, 2014, pp. 2037-2043.

[21] N. Benouzza, A. Benyettou, A. Bendiabdellah, B. Kraloua ,D. Toumi, "Rotor cage fault diagnosis in three-phase induction motors, by Park's vector approach," Jordanian International Electrical Electronics Engineering Conference, 2001.

[22] Q. Lu and T. Breikin, "Observer based fault detection for stator inter-turn short circuit in wind turbine DFIGs," Proceedings of the 2010 International Conference on Modelling, Identification and Control, Okayama, 2010, pp. 483-488.

[23] R. M. Tallam, T. G. Habetler and R. G. Harley, "Transient model for induction machines with stator winding turn faults," in IEEE Transactions on Industry Applications, vol. 38, no. 3, pp. 632-637, May-June 2002.

[24] S. Shao, E. Abdi, F. Barati and R. McMahon, "Stator-Flux-Oriented Vector Control for Brushless Doubly Fed Induction Generator," in IEEE Transactions on Industrial Electronics, vol. 56, no. 10, pp. 4220-4228, Oct. 2009.

[25] S. Bennett, R. Patton, S. Daley, D. Newton, "Model Based Intermittent Fault Tolerance in an Induction Motor Drive," Symposium on Control, Optimization and Supervision, vol. 1, 1996, pp. 678-683.

[26] S. Elaimani, «Modélisation des différentes technologies d'éolienne intégrées dans un réseau de moyenne tension », Mémoire de doctorat, Université des science et de la technologie de Lille, (2004).

[27] S. Ebrahimkhani, "Robust fractional order sliding mode control of doubly-fed induction generator -based wind turbines," ISA Transactions, vol. 63, pp. 343-354, July 2016.

[28] T. Ghennam, E. M. Berkouk and B. Francois, "Modeling and control of a Doubly Fed Induction Generator (DFIG) based Wind Conversion System," 2009 International Conference on Power Engineering, Energy and Electrical Drives, Lisbon, 2009, pp. 507-512.

[29] V. Dinkhauser, W. Friedrich, "Detection of Rotor Turn-to-Turn Faults in Doubly-Fed Induction Generators in Wind Energy Plants by means of Observers," in Conference: Power Electronics and Applications, 2009.

[30] Xianrong Chang, V. Cocquempot and C. Christophe, "A model of asynchronous machines for stator fault detection and isolation," in IEEE Transactions on Industrial Electronics, vol. 50, no. 3, pp. 578-584, June 2003.

[31] X. Zheng, R. Song and H. Li, "Full-order terminal sliding mode stator flux observer for DFIG," 2016 IEEE 11th Conference on Industrial Electronics and Applications (ICIEA), Hefei, 2016, pp. 299-303.

[32] F. Mellah contribution a la commande basee sur la passivite avec un observateur mode glissant des systemes electromecaniques "Application au moteur asynchrone" Thèse de doctorat. USTO Oran Algerie. 2013

[33] H. Chekireb, M. Tadjine, and M. Djemai, "Robustness analysis on sliding mode control of induction motor," Asian Journal of Control, vol. 5, no. 4, pp. 605-613, December 2003.

\section{APPENDIX}

Table 1. Different Parameters for Model of the DFIG

\begin{tabular}{lcc}
\hline \multicolumn{1}{c}{ Electrical } & Index & Value \\
\hline Rated power & $P_{s}$ & $7500 \mathrm{~W}$ \\
Stator resistance & $R_{s}$ & $0.440 \Omega$ \\
Rotor resistance & $R_{r}$ & $0.59 \Omega$ \\
Stator leakage inductance & $L_{s}$ & $0.0072 \mathrm{H}$ \\
Rotor leakage inductance & $L_{r}$ & $0.0079 \mathrm{H}$ \\
Magnetizing inductance & $L_{m}$ & $0.0070 \mathrm{H}$ \\
Number of pole pairs & $P$ & 2 \\
Inertia & $J$ & $0.31102 \mathrm{~kg} \cdot \mathrm{m}^{2}$ \\
Viscous friction & $f_{v}$ & $0.00654 \mathrm{~kg} \cdot \mathrm{m}^{2} \cdot \mathrm{s}^{-1}$ \\
\hline
\end{tabular}


Table 2. Variation of Wind Speed

\begin{tabular}{clll}
\hline $\mathrm{t}(\mathrm{s})$ & 0 & 4 & 7 \\
\hline $\mathrm{V}(\mathrm{m} / \mathrm{s})$ & 10 & 12 & 14 \\
Qsref (var) & 0 & 0 & 0 \\
\hline
\end{tabular}

Table 3. The Degree of Short-circuit

\begin{tabular}{ccc}
\hline $\mathrm{t}(\mathrm{s})$ & 0 & 0.9 \\
\hline$\gamma_{(\%)}$ & 0.10 & 4 \\
\hline
\end{tabular}

Table 4. Change in $R_{r 1}$

\begin{tabular}{ccc}
\hline \multicolumn{1}{c}{$(\mathrm{s})$} & 0 & 1.29 \\
\hline$R_{r 1}{ }_{(\Omega)}$ & $R_{r}$ & $R_{r}+50 \% R_{r}$ \\
\hline
\end{tabular}

